\title{
Experimental Investigation of Damping Performance of Viscoelastic Materials
}

\author{
Siddharth D. Owal* and S. B. Sanap \\ Mechanical Engineering Department, Savitribai Phule Pune University, Pune, Maharashtra, India
}

Accepted 15 June 2016, Available online 20 June 2016, Special Issue-5 (June 2016)

\begin{abstract}
Damping is a critical parameter that needs to be studied for different materials. Hence the best suitable material can be used for a particular application. In metal structure damping is low, which results in high amplitude of vibration. Hence instead of metals, viscoelastic materials can be used as a damping material. These materials are capable of storing energy when deformed and dissipate a portion of energy through hysteresis. The damping performance of the viscoelastic materials are investigated using constrained layer damping treatment. An experimental investigation is carried out to determine damping factor using different viscoelastic materials as the core layer in the constrained layer damping structures using Fast Fourier Transform analyser. The amount of damping of structure is measured by logarithmic decrement method. This method of damping treatment is widely used for structural application in many industries like automobiles, aerospace etc.
\end{abstract}

Keywords: Viscoelastic material (VEM), constrained layer damping (CLD), Logarithmic decrement, Damping factor.

\section{Introduction}

The damping of materials is always overlooked criterion for mechanical system design. The lack of damping in structural materials has led to many mechanical failures. Damping in metals is low which results in high amplitude of vibrations. The current damping materials present in market is viscoelastic materials (VEM) which is having a behavior which falls between both plastic and elastic extremes.

A body once set to vibrate freely, will not vibrate for indefinite time. The amplitude of the vibration goes on decreasing and becomes zero as a result of friction. The body is said to be damped. An undamped material once excited, will oscillates for indefinite time with constant amplitude. Any physical system, however, possesses some internal forces because of which energy dissipated during a cycle of vibration. The rate at which the energy is dissipated is depends on the properties of the materials. The damping characteristics are important for selecting new engineering materials. The material which damps off quickly is preferred on the material which vibrates longer time after the excitation force is removed. (Chowdhury $\mathrm{M}$, et al). Free vibrations that occur for indefinite time with same amplitude don't exist in nature. Amplitude of vibration goes on decresing due to the friction in the oscillating system. This means that free vibrations suffer damping. Such

*Corresponding author: Siddharth D. Owal motion is no longer a periodic one, but is none the less considered a vibratory movement. The damping can be internal or external as Friction occurs between the oscillating system and the environment or internally in the system,. (Glovnea, M, et al, 2009). Dynamic properties such as frequency, damping and mode shapes of a structural element can be described by a process called modal analysis. Structural condition can be monitored by analyzing the changes in frequencies and mode shapes. All materials posses certain amount of internal damping, which manifested as dissipation of energy from the system. This internal energy present in a vibratory system is either dissipated in form of heat or radiated away from the system, (Yasmeen S. et al 2014) In structural damping, viscoelastic materials are used as damping materials as they are capable of storing strain energy when deformed, and dissipate a portion of this energy through hysteresis.

To find out the damping characteristics of viscoelastic materials, the constrained layer damping (CLD) treatment is used. In Constrained layer treatments the damping material is sandwiched between the base structure and a constraining layer. Sandwich specimen is used for determining the damping properties of viscoelastic materials. In symmetrical sandwich beam roots are provide on top of the surface as well as at the bottom of the surface. The presences of roots are essential for most measurements because they give the best simulation of the cantilever conditions when the beam is clamped 
rigidly in the test fixture (Hujare $\mathrm{P}$, et al, 2014). An objective of this work is to find out the best VEM among the five materials over the undamped beam on the basis of damping factor calculated by logarithmic decrement method.

\section{Test beam}

\subsection{Oberst beam}

Aluminium is the typical material for the base beam because it can be easily machined. In this experiment aluminium base beam has been taken as an undamped beam as shown in Fig.1

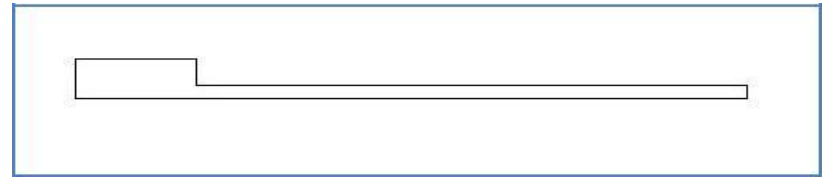

Fig.1: Oberst beam

\subsection{CLD beam}

The CLD beam consists of base beam, constraining layer and the viscoelastic material which is sandwiched in between these two layers by using 3M High strength Acrylic two face adhesive as shown in Fig. 2

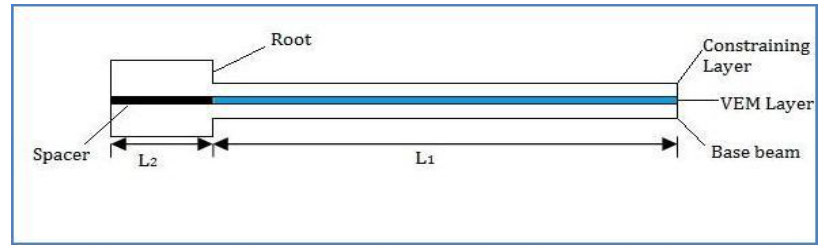

Fig.2: Sandwich CLD beam

The dimensions of sandwich CLD beam are shown in Table 1.

Table 1: Dimensions of beam

\begin{tabular}{|c|c|c|c|}
\hline $\begin{array}{c}\text { Parts } \\
\text { Name }\end{array}$ & $\begin{array}{c}\text { Thickness } \\
(\mathrm{mm})\end{array}$ & $\begin{array}{c}\text { Free } \\
\text { Length } \\
\text { L1(mm) }\end{array}$ & $\begin{array}{c}\text { Width } \\
(\mathrm{mm})\end{array}$ \\
\hline Base beam & 2 & 400 & 50 \\
\hline $\begin{array}{c}\text { Constrained } \\
\text { layer (VEM) }\end{array}$ & 1 & 400 & 50 \\
\hline $\begin{array}{c}\text { Constraining } \\
\text { layer }\end{array}$ & 2 & 400 & 50 \\
\hline
\end{tabular}

\subsection{Material of beam}

Five different viscoelastic materials are considered as constrained layer which are listed in Table 2.
Table 2: Material properties

\begin{tabular}{|c|c|c|}
\hline Material type & $\begin{array}{c}\text { E modulus } \\
(\mathrm{Mpa})\end{array}$ & $\begin{array}{c}\text { Density } \\
\left(\mathrm{Kg} / \mathrm{m}^{3}\right)\end{array}$ \\
\hline Base beam & 69000 & 2700 \\
\hline Constraining layer & 69000 & 2700 \\
\hline $\begin{array}{c}\text { Constrained layer } \\
\text { (VEM) }\end{array}$ & & \\
\hline 1.Neoprene & 11.51 & 1483 \\
\hline 2. Nitrile & 10.33 & 920 \\
\hline 3. Butyl & 10.67 & 940 \\
\hline $\begin{array}{c}\text { 4. Styrene } \\
\text { butadiene } \\
\text { rubber (SBR) }\end{array}$ & 10.35 & 1271 \\
\hline $\begin{array}{c}\text { 5. Poly Vinyl } \\
\text { Chloride (PVC) }\end{array}$ & 41.53 & 1000 \\
\hline
\end{tabular}

\section{Experimental Set up}

The experimental set up for the vibration of cantilever sandwich beam is shown in Fig. 3. Experimental set up consist of CLD beam, a fixture, an accelerometer uniaxial type 4515 (B \& K), an impact hammer 8206002, FFT analyzer 4 channel (B \& K). The FRF response can be seen by using RT Pro software (B \& K software Help 2009). The sandwich CLD beam is shown in Fig.1

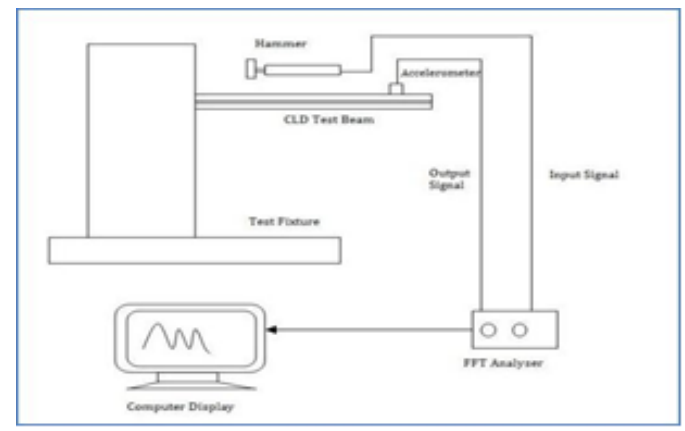

Fig. 3: Experimental Set up

After giving an impact on a sandwich beam FRF values and Time-domain was obtained with the help of RT pro software.

\section{Logarithmic decrement}

For a linear system of vibration the ratio of the amplitude for any given cycle of vibration to the amplitude of another cycle is a constant, this constant is called the logarithmic decrement $(\delta)$, which is defined as proportional to the natural logarithm of the ratio of two amplitudes which are apart at a multiple of time period as in Eq.1 and damping factor in Eq.2. Motion decay of damping is shown in Fig.4.

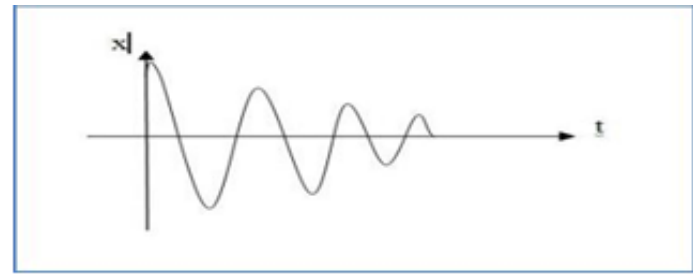

Fig. 4: Motion Decay of damping 
Logarithmic decrement $(\delta)$ is given by,

$\delta=(1 / \mathrm{M}) \cdot \ln (\mathrm{x} 1 / \mathrm{xm}+1)$

Where

$\mathrm{M}=$ No. of cycles

Damping factor (ל) is given by,

$\zeta=\delta /\left(4 \pi^{2}+\delta^{2}\right)^{1 / 2}$

\section{Results and Discussion}

The FRF curves and Time domain for undamped beam,

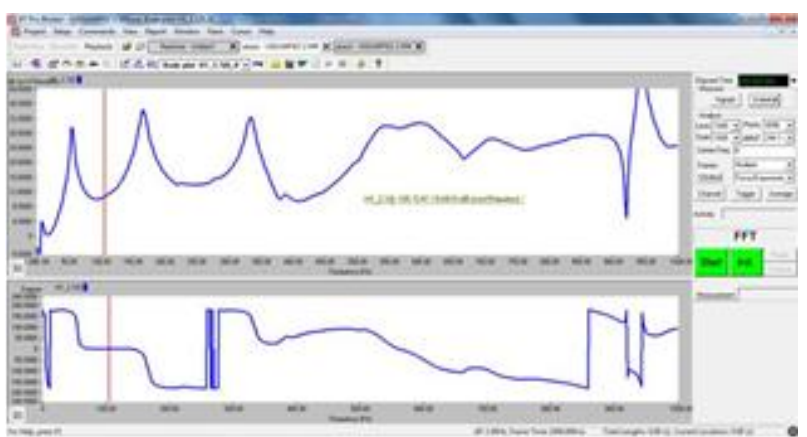

Fig. 5: Frequency response function (FRF) curve of undamped beam

Natural frequencies and amplitude values obtained from Fig. 5 for undamped beam is given in Table 3 .

Table 3: Frequency response values for undamped beam

\begin{tabular}{|c|c|c|}
\hline Mode No & $\begin{array}{c}\text { Natural } \\
\text { Frequency (Hz) }\end{array}$ & $\begin{array}{c}\text { Vibration response } \\
\text { amplitude (dB) }\end{array}$ \\
\hline 1 & 8 & 4 \\
\hline 2 & 55 & 29.53 \\
\hline 3 & 166 & 34.33 \\
\hline 4 & 334 & 32.23 \\
\hline
\end{tabular}

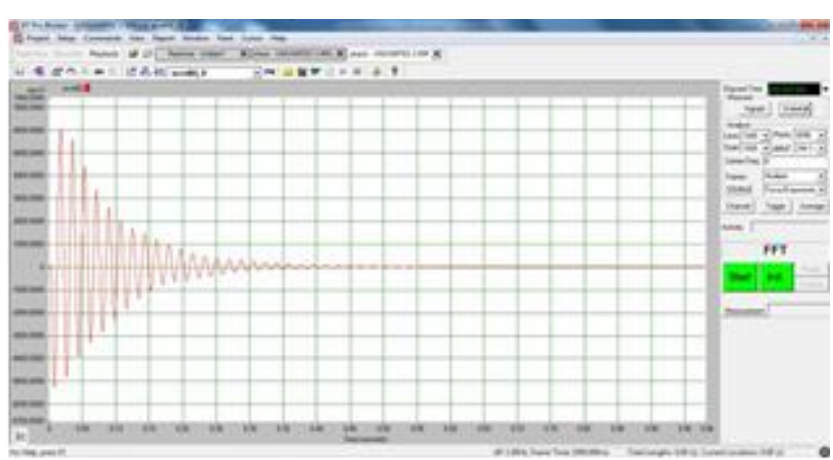

Fig. 7: Time domain o/p by FFT analyzer for undamped beam

Time domain for undamped beam is shown in Fig.7 $\mathrm{x} 1=6$ and $\mathrm{x} 2=5.5$

Logarithmic decrement is given by,

$\delta=(1 / \mathrm{M}) \cdot \ln (\mathrm{x} 1 / \mathrm{xm}+1)$

$\mathrm{M}=1$

$\delta=\ln (6 / 5.5)$

$\delta=0.08701$

Damping factor is given by,

$\zeta=\delta /\left(4 \pi^{2}+\delta^{2}\right)^{1 / 2}$

$\zeta=0.08701 /\left(4 \pi^{2}+0.08701^{2}\right)^{1 / 2}$

$\zeta=0.08701 / 6.2838$

$\zeta=0.01384$

The FRF curves and Time domain for Nitrile CLD beam,

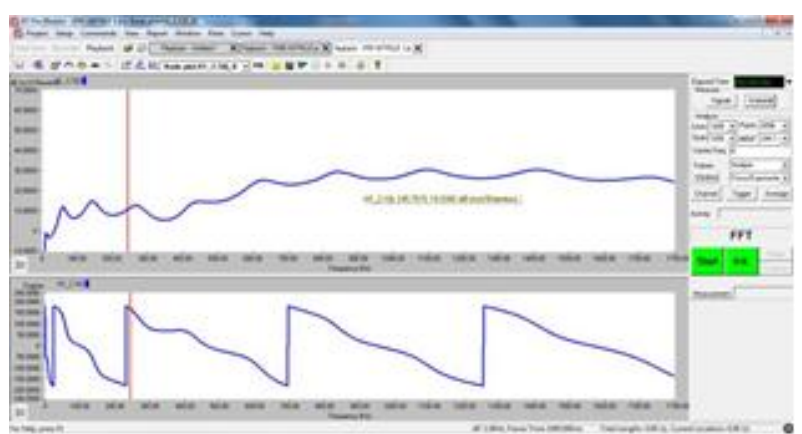

Fig. 6: Frequency response function (FRF) curve of Nitrile CLD beam

Natural frequencies and amplitude values obtained from Fig. 6 for undamped beam is given in Table 4 .

In Fig. 5 and Fig. 6, lower half shows the relation between phase angle and frequency. This phase angle is important to identify resonance frequencies.

Table 4: Frequency response values for Nitrile CLD beam

\begin{tabular}{|c|c|c|}
\hline Mode No & Natural & $\begin{array}{c}\text { Vibration } \\
\text { response }\end{array}$ \\
\cline { 3 - 3 } & Frequency (Hz) & amplitude (dB) \\
\hline 1 & 12 & 1 \\
\hline 2 & 61 & 12.10 \\
\hline 3 & 144 & 14.63 \\
\hline 4 & 268 & 12.68 \\
\hline
\end{tabular}

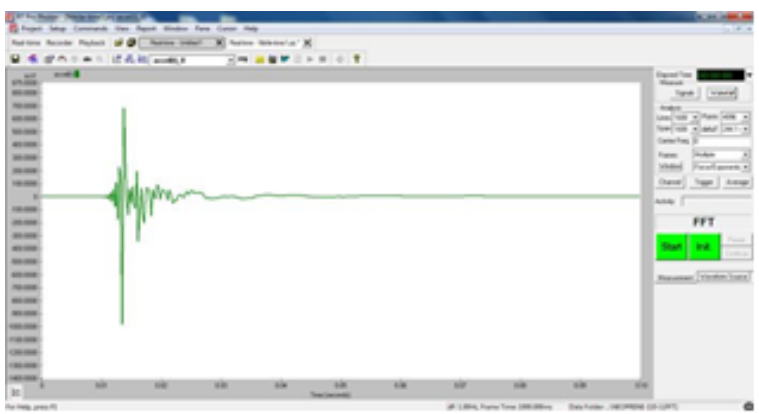

Fig. 8: Time domain o/p by FFT analyzer for Nitrile CLD beam 
Time domain for Nitrile is shown in Fig.8

$\mathrm{x} 1=6.5$ and $\mathrm{x} 2=0.5$

Logarithmic decrement is given by,

$\delta=(1 / \mathrm{M}) \cdot \ln (\mathrm{x} 1 / \mathrm{xm}+1)$

$\mathrm{M}=1$

$\delta=\ln (6.5 / 0.5)=2.5649$

Damping factor is given by,

$\zeta=\delta /\left(4 \pi^{2}+\delta^{2}\right)^{1 / 2}$

$\zeta=2.5649 /\left(4 \pi^{2}+2.5649^{2}\right)^{1 / 2}$

$\zeta=0.3779$

The vibration response amplitude is considered for mode 2. Results are given in Table 5 .

Table 5: Damping performance

\begin{tabular}{|c|c|c|}
\hline Parameters & $\begin{array}{c}\text { Undamped } \\
\text { beam }\end{array}$ & Nitrile \\
\hline $\begin{array}{c}\text { Natural } \\
\text { Frequency (Hz) }\end{array}$ & 55 & 61 \\
\hline $\begin{array}{c}\text { Vibration } \\
\text { response } \\
\text { amplitude (dB) }\end{array}$ & 29.53 & 12.10 \\
\hline $\begin{array}{c}\text { Damping factor } \\
(\zeta)\end{array}$ & 0.013847 & 0.3779 \\
\hline
\end{tabular}

\section{Conclusion}

The main objective of the present work is to study the vibration damping characteristics of undamped beam and different Viscoelastic Materials. This method is Non destructive testing method.
The cantilever beams have been subjected to free vibration and damping ratio has been computed by using Logarithmic decrement method.

On the basis of this work following conclusions are drawn,

1. From the analysis it is found that natural frequency for undamped beam is lower than sandwich CLD beam with Nitrile as constrained layer.

2. The vibration response amplitude is lower for sandwich CLD beam with Nitrile as constrained layer compared to undamped beam.

3. The damping factor of sandwich CLD beam with Nitrile as constrained layer is higher than undamped beam. Hence vibrations in CLD beam damped out earlier.

\section{References}

Chowdhury, M.R. and Chowdhury, F., Experimental Determination of Material Damping Using Vibration Analyzer, N 90-24358

Glovnea, M., Diaconescu E., Ciornei M., (2009), Experimental Investigations of Wood Damping and Elastic Modulus, DOCT-US

Hujare, P.P. and Sahasrabudhe, A.D.(2014), Experimental Investigation of damping performance of viscoelastic material using constrained layer damping treatment, procedia materials science, pp. 726-733

S. A. Yasmeen, Dr.D.Srinivasa Rao, A. P. Anatha.,(2014) Dynamic Characterstic Estimation of Structural Materials by Modal Analysis Using ANSYS, International Journal of Advance Research In Science And Engineering 2014, vol. 3 ISSN-2319-8354(E)

Shridhar, I and Venktesha, C.S. (2013), Influence of Liquid Environments on the Damping Property of Polymer Composites, International Journal of Engineering Research \& Technology, vol.2 Issue 2, ISSN: 2278-0181 